\title{
The intravenous use of commercial disinfectants in the treatment of Novel Coronavirus (COVID-19): Unconventional, but is there evidence against it?
}

\author{
Adarsh Shah', Edmund Leung ${ }^{2}$ \\ ${ }^{1}$ Senior Clinical Research Fellow, Centre of Healthcare Education and Research, University of Aberdeen, Aberdeen, \\ AB25 2ZD, ${ }^{2}$ Consultant Surgeon, Base Hospital, Westown, New Plymouth, New Zealand 4310
}

A B S T R A C T

Background: On 24 ${ }^{\text {th }}$ April 2020, United States President Donald J. Trump suggested the use of commercial surface disinfectants to treat patients infected with COVID-19. In his speech, President Trump also proposed medical research be conducted. However, there are controversies regarding the toxicity of the disinfectant's main ingredients sodium hypochlorite. Aims and Objective: The purpose of this international collaborative study is to assess on feasibility and safety of disinfectants in human use. Materials and Methods: Several safety labels of common commercialised brands of surface disinfectant from United Kingdom and New Zealand. Furthermore, literature search was conducted through Pubmed on keywords keywords "sodium hypochlorite" AND "poisoning" AND "intravenous drug user". Result: All safety labels advised hazardous warning regarding irritation and caustic burns if ingested. They all suggest water to wash out the effect if exposed to any mucus membrane such as eyes and broken skin. No safety information was given by any of the brands against subcutaneous or intravenous injection. No death in human was reported resulting from oral ingestion. There were 2 case reports: one of blindness and one of fibrosing alveolitis resulting from ingestion during a domestic dispute. Intravenous injection has only been seen in attempted murder cases or by intravenous drug users. All the reported cases have resulted in 2 deaths, organ failures and venous thrombosis including pulmonary embolism. Conclusion: There is no safety warning from the manufacturers of the studied surface disinfectants regarding intravenous use. Intravenous injections in the literature suggests significant toxic outcome including death. Randomised controlled trials on animals may be required to assess the risk of intravenous injection of surface disinfectants against the risk of death from COVID-19 infection.

\section{Website:}

http://nepjol.info/index.php/AJMS DOI: 10.3126/ajms.v11i4.28941

E-ISSN: 2091-0576

P-ISSN: 2467-9100

Copyright (c) 2020 Asian Journal of Medical Sciences

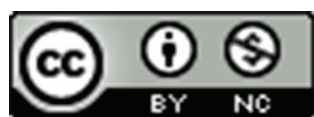

This work is licensed under a Creative Commons Attribution-NonCommercial 4.0 International License.

\section{INTRODUCTION}

On $23^{\text {rd }}$ April 2020, United States President Donald J. Trump stated "And then I see the disinfectant where it knocks it [the virus] out in a minute. One minute. And is there a way we could do something like that, by injection inside or almost a cleaning?". ${ }^{1}$ The statement led to a chain reaction of outrage from the medical community on social media. Leading on that, the authors decided to dissect and investigate this controversial claim.

\section{MATERIALS AND METHODS}

Sodium Hypochlorite $(\mathrm{NaOCl})$ is utilised in dental procedures, $^{2}$ as topical cutaneous disinfectants ${ }^{3}$ and 
formulations containing $\mathrm{NaOCl}$ have been trialled in the management of dermatitis. ${ }^{4}$ Intravenous drug users (IVDUs) use it to clean needles, and in the early days of the HIV / AIDS discovery, the use of bleach was advocated to clean needles in the hope of preventing the spread of blood-borne viruses. ${ }^{5} \mathrm{~A}$ few IVDUs even purposely inject bleach intravenously bleach in order to reverse opioid effects.

A literature search on Pubmed using the keywords "sodium hypochlorite" and "poisoning" and "intravenous drug user" revealed only three case reports. A search on the National Poisons Information Service revealed no specific information on the management of intravenous sodium hypochlorite poisoning, other than organ system support. $^{6}$

\section{RESULTS AND DISCUSSION}

Safety labels of twenty common commercialised domestic brands of surface disinfectant from the United Kingdom and New Zealand were inspected. $\mathrm{NaOCl}$ was the commonest active ingredient, with strengths varying from $0.52 \%$ to $4.5 \%$. Other products comprised Benzalkonium chloride, chloroxylenol and chlorocresol. Most safety labels contained advise on managing accidental eye and skin contact. In two of ten UK products, explicit advice against oral ingestion of the product either in text or representative symbol was present. In such cases, seeking urgent medical care was advised. No safety information was given by any of the brands against subcutaneous or intravenous injection.

Intravenous injection has been seen in attempted murder cases or by intravenous drug users. All the reported cases have resulted in two deaths, organ failures and venous thrombosis including pulmonary embolism. No animal studies or randomised controlled trials have been conducted. In his speech, President Trump also proposed medical research be conducted. Based on our literature search, there is no convincing evidence for or against the injection of disinfectant in the treatment of the novel Coronavirus (COVID-19). However, the medical community has significant concerns with regards to the safety aspect of injection of commercially available disinfectant.

The COVID-19 pandemic has not only caused chaos worldwide, but many lives have been lost to the infection. These are unprecedented times. The race to the development of treatment and vaccination against COVID-19 patients has begun. Over the decades, advances have been made in chemotherapeutic agents to treat a plethora of cancers with documented benefits in their oncological outcome. Medical scientists have developed many drugs for the treatment of chronic inflammatory conditions such as Crohn's disease and Rheumatoid arthritis. Collectively, these immunomodulators are known as "biologics" and were hailed to be "novel pharmaceuticals". Intravenous biologics and chemotherapeutic agents are highly toxic and immunosuppressive. At the time of their introduction into clinical practice, clinicians were horrified with intravenous use of these drugs in patients already with an immune compromised condition. ${ }^{7}$ As agonising research has gone on, intravenous use of biologics is now widely accepted by clinicians for many conditions, sometimes even in combination with chemotherapy for certain cancer treatment.

The controversy lies with the toxic effects of commercially available disinfectants. President Trump proposed the idea to the medical community of the possibility of injectable formulations of disinfectants in the fight against COVID-19. It was an unexpected statement from a non-scientifically based politician. Some viewed President Trump's statement, presented in the manner he did, to be dangerous and inappropriate to the general public worldwide given President Trump is a renowned international leader. In the event that intravenous disinfectant wasproven effective against COVID-19 infection, the feasibility and safety of its use needs to be researched. The injectable formulation for human consumption needs to be developed and trialled, initially with animal models. Otherwise, the trial would be analogised as assessment of risk of death from jumping out of a plane with and without a parachute. The dosage would need to be prescribed. The overall feasibility studies will ultimately be based on the assessment of the risk of intravenous injection of surface disinfectants against the risk of death from COVID-19 infection.

\section{CONCLUSION}

There is no safety warning from the manufacturers of the studied surface disinfectants regarding intravenous use. Intravenous injections in the literature suggests significant toxic outcome including death. Randomised controlled trials on animals may be required to assess the risk of intravenous injection of surface disinfectants against the risk of death from COVID-19 infection.

\section{REFERENCES}

1. BBC. NEWS: US \& Canada. [Online].; 2020 [cited 2020 April 27. Available from: www.bbc.co.uk/news/world-uscanada-52407177. 
2. Mohammadi Z. Sodium hypochlorite in endodontics: An update review. Int Dent J. ; 58(6): p. 329-341.

https://doi.org/10.1111/j.1875-595X.2008.tb00354.x

3. Peck B, Workeneh B, Kadikoy $H$, Patel $S$ and Abdellatif $A$. Spectrum of sodium hypochlorite toxicity in man - also a concern for nephrologists. NDT Plus 2011; 4: 231-235.

4. PubChem. Sodium hypochlorite. [Online].; 2020 [cited 2020 April 27. Available from: https://pubchem.ncbi.nlm.nih.gov/ compound/Sodium-hypochlorite.

5. Normand J VDML, editor. National Research Council (US) and Institute of Medicine (US) Panel on Needle Exchange and Bleach Distribution Programs. In. Washington: National Academies Press (US); 1995.

6. National Poisons Information Service. Toxbase. [Online].; 2020 [cited 2020 April 27. Available from: www.toxbase.org.

7. Morgan SJ, Elangbam CS, Berens S, Janovitz E, Vitsky A, ZabkaT, et al. Use of animal models of human disease for nonclinical safety assessment of novel pharmaceuticals. Toxicol Pathol 2013; 41(3): 508-518.

https://doi.org/10.1177/0192623312457273

Authors Contribution:

AS and EL- Contributed equally on data collection and writing the article.

Work attributed to:

Centre of Healthcare Education and Research, University of Aberdeen, Aberdeen and Base Hospital, Westown, New Plymouth, New Zealand 4310.

Orcid ID:

Dr. Edmund Leung - (1) https://orcid.org/0000-0003-3710-1035

Source of support: None, Conflicts of Interest: None 